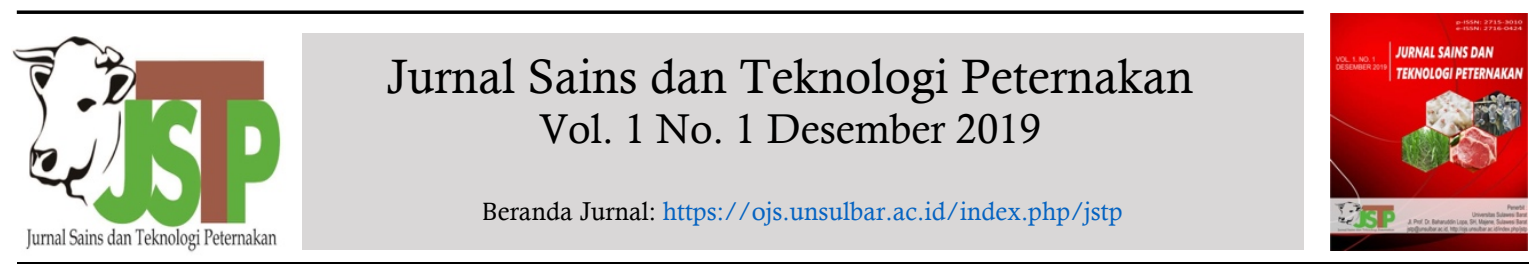

\title{
Laporan Kasus: Penanganan Dipylidiasis pada Kucing Anggora dengan Praziquantel
}

\section{(Case Report: Treatment of Dipylidiasis in Angora Cats with Praziquantel)}

Annisa Putri Cahyani ${ }^{1 *}$, I Nyoman Suartha ${ }^{2}$, dan Nyoman Sadra Dharmawan ${ }^{3}$

${ }^{1}$ Laboratorium Reproduksi dan Kesehatan Hewan, Jurusan Peternakan, Politeknik Pembangunan Pertanian Yogyakarta Magelang, J1. Kusumanegara No.2, POLBANGTAN, YOMA, Kota Yogyakarta, Daerah Istimewa Yogyakarta 55167

${ }^{2}$ Laboratorium Ilmu Penyakit Dalam Veteriner, Fakultas Kedokteran Hewan, Universitas Udayana, ${ }^{3}$ Laboratorium Patologi Klinik Veteriner, Fakultas Kedokteran Hewan, Universitas Udayana, Kampus Bukit, J1. Raya Kampus Unud Jimbaran, Kec. Kuta Sel., Kabupaten Badung, Bali 80361

A R T ICLE INFO

Received: 20 November 2019

Accepted: 30 Desember 2019

*Corresponding author

annisaputri@pertanian.go.id

Keywords:

Angora cat

Dipylidiasis,

Dipylidium caninum,

Praziquantel

\begin{abstract}
A B S T R A C T
Dipylidiasis is a tapeworm disease that attacks cats and dogs and classified as a zoonotic disease because it can be transmitted to humans. A 2 years old female angora cat weighing $3 \mathrm{~kg}$ was examined with complaints of bloody diarrhea for 2 weeks. The results of native faecal examination showed the presence of D. caninum worm eggs. Animals diagnosed with dipylidiasis. Cat cases were treated by administering $50 \mathrm{mg}$ praziquantel therapy with the recommendation of 1 tablet for $10 \mathrm{~kg} / \mathrm{BW}$ orally. In conclusion, the treatment of dipylidiasis by administering praziquantel therapy has proven to be effective.
\end{abstract}

\section{A B S T R A K}

Dipylidiasis merupakan penyakit cacing pita yang menyerang kucing dan anjing dan tergolong penyakit zoonosis karena dapat ditularkan dari hewan ke manusia. Seekor kucing angora betina umur 2 tahun dengan berat badan $3 \mathrm{~kg}$ diperiksa dengan keluhan diare berdarah selama 2 minggu. Hasil pemeriksaan feses natif menunjukkan adanya telur cacing $D$. caninum. Hewan didiagnosa menderita dipylidiasis. Kucing kasus ditangani dengan pemberian terapi praziquantel $50 \mathrm{mg}$ dengan anjuran 1 tablet untuk $10 \mathrm{~kg} / \mathrm{BB}$ secara per oral. Penanganan dipylidiasis dengan pemberian terapi praziquantel terbukti efektif.
Kata Kunci:

Dipylidiasis

Dipylidium caninum

Kucing anggora

Praziquantel 


\section{Pendahuluan}

Dipylidiasis merupakan penyakit cacing pita yang secara primer terjadi pada kucing dan anjing. Penyakit ini merupakan penyakit zoonosis karena dapat ditularkan kepada manusia melalui hospes perantara berupa pinjal atau kutu anjing. Dipylidiasis disebabkan oleh cacing pita Dipylidium caninum yang berpredileksi di usus halus. Manusia terutama anak-anak dapat sebagai occasional host (García-Agudo et al., 2014). Kasus dipylidiasis pada manusia di Indonesia belum pernah dilaporkan. Selain anjing dan kucing sebagai hospes definitif lainnya adalah kucing dan karnivora liar. Gejala spesifik yang dapat diamati adalah ditemukannya rangkaian segmen atau segmen tunggal pada feses, menggosokkan anus pada lantai karena rasa gatal pada area perianal serta keberadaan segmen cacing pada area perianal (Yuniarti \& Lukiswanto, 2013).

Dipylidium caninum merupakan salah satu agen penyebab gangguan gastrointestinal yang umum dijumpai pada kucing. Dipylidium caninum merupakan anggota kelas Cestoda, ordo Cyclophylidea, famili Dipylididae, genus Dipylidium. Tubuh cacing D. caninum terdiri atas kepala, leher dan strobila (Cabello et al., 2011). Kepala cacing pita dilengkapi bothridia, bothria, atau scolex yang berfungsi untuk menempel pada dinding usus. Scolex dilengkapi dengan empat sucker (penghisap). Bagian anterior scolex terdapat organ disebut rostellum yang dilengkapi kait. Cacing D. caninum memiliki ciri khas berbentuk segmen yang dikenal sebagai proglotid, terdiri atas organ reproduksi baik jantan maupun betina dan berisi telur (Ramana et al., 2011)

Dipylidium caninum memiliki panjang sampai $17-70 \mathrm{~cm}$ dan tebal $2-3 \mathrm{~mm}$. Cacing tersebut mempunyai 4 penghisap (sucker) pada skoleksnya untuk melekat dan memperoleh makanan. Puluhan proglotid yang berbentuk oval memiliki alat reproduksi hermaprodit degan 2 buah muara genital yang terletak di sebelah lateral. Terdapat telur dalam jumlah yang banyak di dalam proglottid, disertai dengan kapsul telur yang berbentuk ovoid. Pada setiap kapsul terdapat telur sebanyak 3-30 butir dengan diameter 25-40 $\mu \mathrm{m}$ (Rodan \& Heath, 2015).

Beberapa penanganan kasus dipylidiasis dapat dilakukan dengan pemberian terapi Praziquantel dan Niclosamide (Beugnet et al., 2018; Saini et al., 2016). Penelitian tentang infeksi $D$. caninum pada kucing jarang dilakukan di Indonesia. Laporan kasus mengenai infeksi $D$. caninum dapat digunakan sebagai bahan pertimbangan dalam pengambilan tindakan penanggulangan dan pengendalian penyakit parasitik. Mengingat potensi cacing $D$. caninum sebagai agen zoonotik.patogen.

\section{Materi dan Metode}

\subsection{Sinyalemen dan Anamnesa}

Seekor kucing angora betina umur 2 tahun dengan berat badan $3 \mathrm{~kg}$ diperiksa dengan keluhan diare berdarah selama 2 minggu. Berdasarkan keterangan pemilik, awalnya diare tanpa adanya darah sejak 10 hari, kemudian 4 hari berikutnya ditemukan darah pada feses kucing tersebut. Sejak lahir kucing belum pernah dilakukan vaksinasi maupun pemberian obat cacing. Kucing kasus dipelihara dengan cara dilepasliarkan disekitar rumah. Kucing memiliki nafsu makan dan minum yang baik, dan tetap aktif bergerak. Pakan yang diberikan berupa $d r y$ food dan diberikan secara ad libitum.

\subsection{Pemeriksaan Fisik dan Tanda Klinis}

Status present kucing kasus adalah sebagai berikut: frekuensi detak jantung $104 \mathrm{kali} /$ menit; frekuensi pulsus $104 \mathrm{kali} / \mathrm{menit}$; frekuensi respirasi $28 \mathrm{kali} / \mathrm{menit}$; suhu tubuh $38,6{ }^{\circ} \mathrm{C}$; dan nilai capillary refil time kurang dari dua detik. Pemeriksaan mukosa dan konjunctiva mata sedikit pucat, sementara pemeriksaan klinis seluruh sistem organ normal. Tanda klinis yang terlihat kucing mengalami diare berdarah dan terdapat proglotid cacing pita (Gambar 1A).

\subsection{Pemeriksaan Penunjang}

Pemeriksaan penunjang yang dilakukan adalah pemeriksaan mikroskopis feses secara natif dan pemeriksaan hematologi rutin. Pemeriksaan hematologi rutin kucing kasus dilakukan sebelum dan sesudah diberikan terapi praziquantel.

\subsection{Diagnosa dan Prognosa}

Berdasarkan sinyalemen, anamnesa, temuan klinis, didukung dengan pemeriksaan mikroskopis feses dan hematologi rutin, kucing kasus didiagnosa menderita dipylidiasis dengan prognosa fausta karena melihat kondisi hewan secara umum menunjukkan kondisi yang cukup baik.

\subsection{Penanganan}

Kucing kasus ditangani dengan pemberian terapi praziquantel $50 \mathrm{mg}$ dengan anjuran 1 tablet untuk $10 \mathrm{~kg} / \mathrm{BB}$ secara per oral

\section{Hasil dan Pembahasan}


Isolat Hasil pemeriksaan mikroskopis feses menunjukkan adanya telur cacing Dipylidium caninum (Gambar 1 B). Feses yang mengeluarkan darah menunjukkan adanya iritasi pada mukosa usus (gambar 1A). Pengeluaran feses bercampur darah tersebut biasa disebut melena. Gigitan cacing yang sekaligus melekat pada mukosa segera terjadi perdarahan yang tidak segera membeku. Telur cacing $D$. caninum keluar bersama feses inang vertebrata, selanjutnya termakan oleh larva pinjal bersama sisa-sisa organik. Telur akan berkembang mencapai stadium larva sebagai cysticercoid di rongga tubuh

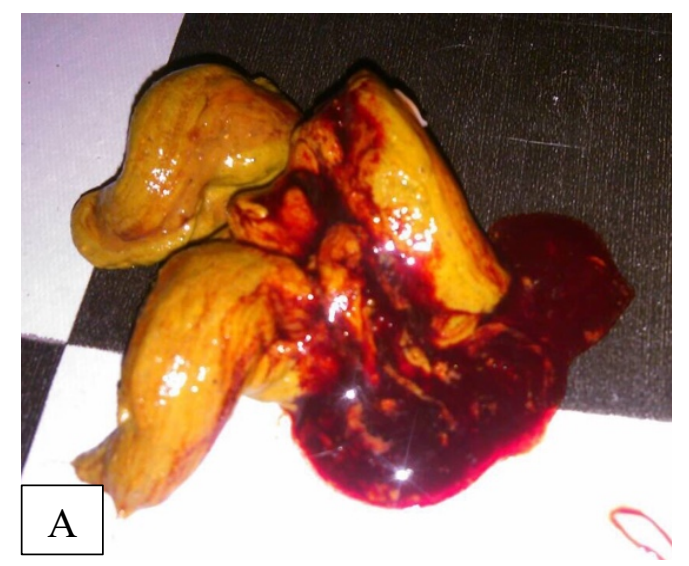

pinjal. Ketika inang vertebrata (kucing) menelan pinjal maka kucing tersebut dapat terinfeksi $D$. caninum. Akhirnya, cysticercoid berkembang dalam tubuh inang vertebrata menjadi cacing dewasa. Cacing dewasa berpredileksi di usus halus dan dalam jumlah besar akan menyebabkan gangguan. Infeksi berat pada hewan muda umumnya muncul gejala klinis yang tidak spesifik seperti konstipasi dan diare (Nemzek et al., 2015). Manusia juga bisa terinfeksi $D$. caninum dan menimbulkan gejala klinis berupa sakit perut, mual, dan muntah (Jayalakshmi et al., 2017).

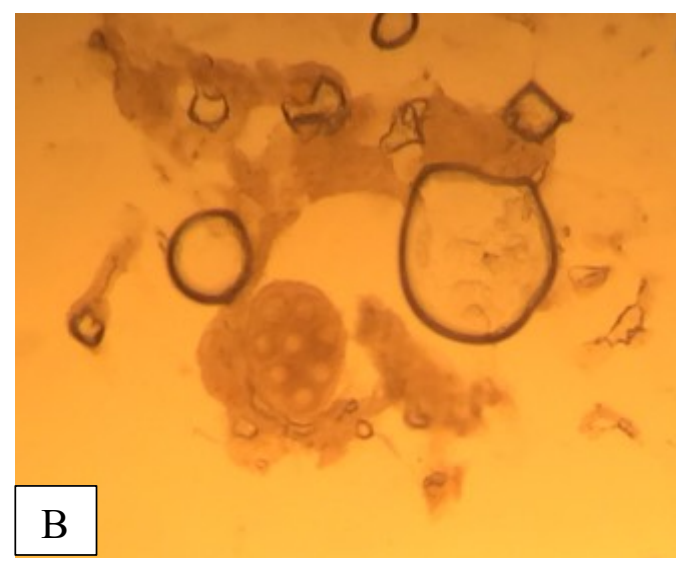

Gambar 1. (A) feses kucing mengalami diare berdarah dan terdapat proglotid cacing pita; (B) Hasil pemeriksaan mikroskopis feses ditemukannya telur cacing D. caninum (perbesaran $10 \mathrm{kali}$ )

Tabel 1. Hasil pemeriksaan hematologi hewan kasus

\begin{tabular}{lrrrr}
\hline Parameter & Nilai normal & Sebelum terapi & $\begin{array}{c}\text { Setelah diberikan } \\
\text { terapi }\end{array}$ & Satuan \\
\hline Hemoglobin & $8-15$ & 7,6 & 8 & $\mathrm{~g} / \mathrm{dL}$ \\
Eritrosit & $5-10$ & 7,4 & 7,5 & $10^{6} / \mathrm{mm}^{3}$ \\
Leukosit & $5,5-19,5$ & 12,7 & 12 & $10^{3} / \mathrm{mm}^{3}$ \\
Trombosit & $300-700$ & 285 & 305 & $10^{3} / \mathrm{mm}^{3}$ \\
Hematokrit & $30-45$ & 26 & 30 & $\%$ \\
Neutrofil & $35-75$ & 53 & 50 & $\%$ \\
Limfosit & $20-55$ & 20 & 20 & $\%$ \\
Monosit & $1-4$ & 7 & 4 & $\%$ \\
Eosinofil & $2-12$ & 15 & 11 & $\%$ \\
Basofil & jarang & - & - & $\%$ \\
MCV & $39-55$ & 35,1 & 39 & $\mathrm{pg}$ \\
MCH & $13-17$ & 10,2 & 13 & $\mathrm{~g} / \mathrm{dL}$ \\
MCHC & $30-35$ & 29,2 & 31 & $\%$ \\
\hline SCH
\end{tabular}

Sumber: Data primer dari pengujian Laboratorium Penyakit Dalam RSH FKH Universitas Udayana

Pemeriksaan hematologi (Tabel 1) dilakukan sebelum terapi praziquantel dan 10 hari setelah diberikan terapi sebagai pembanding guna mengetahui ada tidaknya perubahan pada nilai hematologi kucing kasus. Pemeriksaan hematologi sebelum terapi praziquantel menunjukkan Hemoglobin, PCV/Hematokrit,
$\mathrm{MCV}$, MCHC dan trombosit menurun, sedangkan Monosit dan Eosinofilia mengalami peningkatan. Hal ini menginterpretasi bahwa kucing tersebut mengalami anemia mikrositik hipokromik, monositosis, eosinofilia, dan trombositopenia yang mengindikasikan adanya infeksi kronis dan defisiensi Fe. Menurunnya 
kadar zat besi karena terjadi perdarahan pada usus yang diakibatkan oleh cacing tersebut yang menghisap darah dengan antikoagulan sehingga darah terus menerus mengucur dan bercampur pada feses. Dari hasil tersebut, kucing tersebut diindikasikan mengalami peradangan yang disebabkan oleh infeksi parasit, alergi atau stress. Fungsi utama eosinofil adalah detoksifikasi, baik terhadap protein asing yang masuk ke dalam tubuh melalui paru-paru ataupun saluran cerna maupun racun yang dihasilkan oleh bakteri dan parasit. Eosinofilia dapat terjadi karena infeksi parasit, reaksi alergi dan kompleks antigenantibodi setelah proses imun (Frandson, 1993). Hal ini juga memperkuat bahwa kucing tersebut terinfeksi parasit dan dibuktikan oleh pemeriksaan feses yang menunjukkan positif infeksi Dypilidium caninum.

Pengobatan yang diberikan adalah Praziquantel. Praziquantel merupakan anthelmentik terutama untuk cestoda yang merupakan derivate dari pirazinoiskuinolin. Terhadap taeniasis kucing termasuk dipylidiasis, obat yang dianjurkan adalah sebagai berikut. Praziquantel (Droncit) dosis $6,3 \mathrm{mg} / \mathrm{kg}$ untuk kucing berat kurang dari $1,8 \mathrm{~kg}$, sedang untuk yang lebih berat dari $1,8 \mathrm{~kg}$ dianjurkan $5 \mathrm{mg} / \mathrm{kg}$. Episprantel (Cestex), dengan dosis $2,75 \mathrm{mg} / \mathrm{kg}$ (Subronto, 2010). Obat ini terabsorbsi secara cepat pada pemberian per-oral dan dimetabolisme dalam hepar sebelum dieskresikan ke dalam empedu. Metabolisme obat berlangsung cepat melalui proses hidroksilasi dan konjugasi. Kadar maksimal dalam darah tercapai dalam waktu 1-2 jam. Metabolitnya sebagian besar diekskresikan bersama urin dan sedikit diekskresikan dalam bentuk utuh. Hasil uji hematologi setelah diberikan terapi praziquantel menunjukkan terjadi penurunan nilai eosinophil. Nilai Hemoglobin dan Trombosit mengalami kenaikan (Tabel 1). Praziquantel bekerja melalui dua cara. Pertama, pada kadar efektif terendah menimbulkan peningkatan aktivitas otot pada cacing karena hilangnya ion Ca intrasel, sehingga timbul kontraksi dan paralisis spasifik yang bersifat reversible. Hal tersebut menyebabkan terlepasnya cacing yang menempel pada dinding usus. Kedua, pada dosis terapi yang lebih tinggi praziquantel dapat menyebabkan terjadinya vakuolisasi dan vesikuolisasi pada cacing, sehingga isi cacing keluar dan dapat menyebabkan kematian pada cacing (Plumb, 2018).

\section{Kesimpulan}

Kucing kasus Dipylidiasis yang ditangani dengan terapi pemberian praziquantel sebanyak 2 kali menunjukkan hasil yang efektif dan kesembuhan kasus terjadi cukup cepat yaitu pada hari ke-10 pasca pemberian terapi. Perlakuan untuk mempercepat kesembuhan infeksi, maka diperlukan penanganan kasus dipylidiasis. Sebaiknya dilakukan manajemen pemberian pakan, kebersihan hewan dan lingkungan, serta pemberian obat cacing secara teratur. Perlu dilakukan penelitian lebih lanjut tentang pengaruh pemberian praziquantel dengan sampel yang lebih banyak.

\section{Ucapan Terima Kasih}

Terima kasih diucapkan kepada seluruh staf Laboratorium Penyakit Dalam Veteriner Fakultas Kedokteran Hewan Universitas Udayana yang telah memfasilitasi dan membantu penanganan hewan kasus.

\section{Daftar Pustaka}

Beugnet, F., Labuschagne, M., de Vos, C., Crafford, D., \& Fourie, J. (2018). Analysis of Dipylidium caninum tapeworms from dogs and cats, or their respective fleas: Part 2. Distinct canine and feline host association with two different Dipylidium caninum genotypes. Parasite, 25.

Cabello, R. R., Ruiz, A. C., Feregrino, R. R., Romero, L. C., Feregrino, R. R., \& Zavala, J. T. (2011). Dipylidium caninum infection. BMJ Case Reports, 2011. https://doi.org/0.1136/bcr.07.2011.4510

Frandson, R. D. (1993). Anatomi dan Fisiologi Ternak. Gadjah Mada University Press.

García-Agudo, L., García-Martos, P., \& Rodríguez-Iglesias, M. (2014). Dipylidium caninum infection in an infant: A rare case report and literature review. Asian Pacific Journal of Tropical Biomedicine, 4, S565S567.

Jayalakshmi, L., Katyayani, Y., Madhurima, K., \& Sasikala, G. (2017). Human Dipylidiasis - A rare case report from Hyderabad. IOSR Journal of Dental and Medical Sciences, 16(6), 100-102. https://doi.org/10.9790/0853160609100102

Nemzek, J. A., Lester, P. A., Wolfe, A. M., Dysko, R. C., \& Myers Jr, D. D. (2015). Biology and Diseases of Dogs. In Laboratory Animal Medicine (pp. 511-554). Elsevier. 
Plumb, D. C. (2018). Plumb's Veterinary Drug Handbook (6th ed.). John Wiley \& Sons.

Ramana, K. V, Rao, S. D., Rao, R., Mohanty, S. K., \& Wilson, C. G. (2011). Human dipylidiasis: A case report of Dipylidium caninum infection from Karimnagar. Online Journal of Health and Allied Sciences, 10(2).

Rodan, I., \& Heath, S. (2015). Feline Behavioral Health and Welfare. Elsevier Health Sciences.

Saini, V. K., Gupta, S., Kasondra, A., Rakesh, R. L., \& Latchumikanthan, A. (2016). Diagnosis and therapeutic management of Dipylidium caninum in dogs: a case report. Journal of Parasitic Diseases, 40(4), 14261428.

Subronto. (2010). Penyakit Infeksi Parasit dan Mikroba pada Anjing dan Kucing (2nd ed.). Gadjah Mada University Press.

Yuniarti, W. M., \& Lukiswanto, B. S. (2013). Infeksi Dipylidium caninum pada kucing. Vetmedika Jurnal Klinik Veteriner, 1(2), 5255. 